\title{
Cambio tecnológico y productividad en la industria algodonera española. Una aportación desde la perspectiva empresarial: La España Industrial (1855-1930)
}

\author{
Technological change and productivity in Spanish cotton industry. \\ A contribution from business history: La España Industrial (1855-1930)
}

\author{
ÁNGEL CALVO CALVO \\ Universidad de Barcelona
}

\begin{abstract}
RESUMEN
Este artículo tiene como objetivo contribuir al debate sobre los factores del crecimiento económico a través del estudio de la relación entre cambio tecnológico y productividad en una industria intensiva en mano de obra, la algodonera. Es una apuesta por el largo plazo y por la perspectiva de la historia empresarial como vía para esclarecer aspectos cruciales de la historia económica poco conocidos a nivel agregado. Así, a partir de fuentes primarias, se analiza el caso de La España Industrial, una gran empresa urbana integrada. Como novedad metodológica reivindica medir la productividad en unidades físicas homogéneas para evitar distorsiones en las series. La evidencia empírica revela que, entre otras estrategias de cierta complejidad adoptadas, el cambio tecnológico permitió a algunas empresas afrontar selectivamente la fuerte competencia interna con aumentos de productividad. Nuevos casos, no obstante, han de ser investigados hasta obtener una visión agregada de la evolución de la productividad en la industria española.
\end{abstract}

PALABRAS CLAVE: Cambio tecnológico, Productividad, Industria algodonera, España contemporánea Códigos JEL: N1, N6, O3, O4

\section{ABSTRACT}

The main aim of this article is to contribute to the debate on economic growth factors through the study of the relationship between technological change and productivity in a labour-intensive industry, as cotton. The study emphasizes the value of a long-term business history perspective to clarify key aspects of economic history little known at added level. Thus, from primary sources, the article analyzes the case of La España Industrial, an integrated big urban firm. As a methodological novelty it vindicates expressing productivity in a homogenous measure to avoid inevitable distortions in the series. The empirical evidence reveals that, among other strategies of certain complexity adopted, technological change allowed some companies to face strong domestic competition with increases on productivity. However, new case studies have to be analyzed until having a detailed overview of the evolution of productivity in the Spanish industry.

KEY WORDS: Technological change, Productivity, Cotton industry, Contemporary Spain

JEL Codes: N1, N6, O3, O4 


\section{Introducción ${ }^{1}$}

E ste artículo explora los factores del crecimiento económico y, por tanto, uno de los temas esenciales de la Historia Económica. Para mayor precisión, estudia la relación entre cambio tecnológico y productividad en un sector intensivo en mano de obra como es la industria algodonera ${ }^{2}$. Su objetivo primordial es realizar una aportación al debate internacional desde la perspectiva de la historia empresarial y en una doble dirección. Por un lado, investiga las relaciones entre productividad y cambio tecnológico. Por otro, reivindica la necesidad de medir y expresar la productividad en unidades físicas homogéneas. De esta manera, el estudio se inserta plenamente en diversas corrientes, tradicionales y novedosas, de la historiografía internacional sobre la industria algodonera ${ }^{3}$. Para empezar, sigue a Lazonick en su reivindicación de la perspectiva histórica como elemento fundamental para mostrar que la evolución de la productividad de los factores en la industria algodonera es un complejo proceso en el que intervienen fuerzas económicas, sociales y tecnológicas ${ }^{4}$. Sin embargo, a diferencia de otros autores, el estudio sitúa el factor tecnológico en primer plano y se acerca con parsimonia a los procesos de cambio ${ }^{5}$. De acuerdo con David y Wright ${ }^{6}$, no se busca aquí una pura explicación tecnológica del aumento de la productividad, sino una conceptualización más compleja, que ilustre los aspectos

[Fecha de recepción del original, abril de 2005. Versión definitiva, febrero de 2006]

1 Este trabajo se inscribe en el marco de un proyecto de investigación sobre las relaciones entre tecnología, calificación y género, cofinanciado por la CICYT y el Instituto de la Mujer (Madrid). Versiones preliminares y partes del mismo fueron presentadas en el Third Workshop of The British Academy Network, organizado por P. Sáiz y J. M. Ortiz Villajos (Madrid, 2005); en el VIII Congreso de la European Business History Association (Barcelona, 2004) y en el congreso del International Committee for the History of Technology (Moscú-San Petersburgo, 2003). Agradezco los comentarios y observaciones de los asistentes a las sesiones respectivas, especialmente los de P. Sáiz, I. Inkster, K. Bruland, M. B. Rose y P. Scranton. Estoy en deuda con C. Borderías, investigadora principal del proyecto, que elaboró la costosísima base de datos de los Libros de Semanales, y con C. Villar, autora del diseño técnico y de los cálculos estadísticos a partir de la mencionada base de datos. En el proceso de revisión y mejora del texto, no puedo olvidar las agudas críticas y observaciones de C. Borderías, P. Sáiz y D. Tirado, entre otros, junto a las de los cuatro evaluadores anónimos de Investigaciones de Historia Económica. Por descontado, los errores o deficiencias que puedan persistir son de mi entera responsabilidad.

2 Van Ark y Kuipers (2000); Lindner (2002).

3 Uno de los estudios pioneros sobre los costes reales es el de Jones (1933). Entre las aportaciones más recientes, destacan las de Broadberry (1997), Rose (2000), Broadberry y Marrison (2002) y Jeremy (2004), el último de los cuales incorpora la perspectiva internacional.

$4 \quad$ Lazonick (1981), pp. 496 y ss.

5 Saxonhouse y Wright (2004). Algunos especialistas han subrayado la introducción de tecnología ahorradora de trabajo y no sólo de tiempo; véase Von Tunzelman (1995). Hay quienes atribuyen el crecimiento de la productividad a factores no estrictamente tecnológicos, como la intensificación del trabajo (Bowden y Higgins, 1999) o la participación de los obreros en los beneficios (Huberman, 2001).

6 David y Wright (1991). 
globales y específicos del cambio tecnológico. Esta senda lleva de forma natural a introducir el contenido de género, meta primordial del proyecto en que se inscribe este artículo y objeto, por su parte, de una encendida polémica internacional ${ }^{7}$.

En su vertiente metodológica, el estudio se alinea con quienes reivindican medidas homogéneas para expresar la productividad. Años atrás, P. K. O’Brien ya había llamado la atención sobre los problemas que acarreaba a las comparaciones internacionales la falta de homogeneidad en las medidas del producto. Más recientemente, y refiriéndose a la industria algodonera, T. Leunig ha reclamado una aproximación más adecuada a la medida de la productividad, tras recordar que las estimaciones precedentes expresan la producción por el peso, medida pobre que olvida la finura o grosor del hilo 8 . Finalmente, desde otro punto de vista, G. Clark proporciona el enfoque que vincula un estudio sectorial con el crecimiento económico o la ausencia del mismo9.

El entronque de la historiografía española actual con el debate internacional tiene lugar de forma especial a través de la polémica sobre la competitividad, aspecto directamente vinculado a la productividad. La escasa competitividad fue un argumento muy usado por los industriales para reclamar el proteccionismo o para combatir las reglamentaciones gubernamentales en materia de salarios o de jornadas de trabajo $^{10}$. En los estudios recientes, la escasa competitividad internacional de la industria algodonera española se explica por motivos diversos: unos la achacan a factores internos de la propia industria, en sus fases de producción ${ }^{11}$ o de comercialización ${ }^{12}$, y otros la atribuyen a razones externas, como la estrechez del mercado interno ${ }^{13}$ y las propias características del comercio internacional ${ }^{14}$. Con todo, pese a

O'Brien (1995); Leunig (2001a), (2001b) y (2003). Leunig considera poco fiables las cifras de los censos, excesivamente agregadas para calcular la productividad de forma ajustada. Este autor hace del logro de una medida homogénea la base para su revisión de un tema tan esencial como el de las productividades de la industria algodonera del Lancashire y de Estados Unidos.

Clark (1987); Clark y Feenstra (2001).

$10 \quad$ Ferrer Vidal (1875); Instituto de Reformas Sociales (1914), p. 48. Un análisis de la situación a finales del siglo XIX y comienzos del XX en Calvo (2002).

11 J. Maluquer imputa la falta de competitividad de la industria catalana en el exterior a las diferencias de costes provocadas por el elevado precio de los combustibles de importación, a la deficiente estructura de la misma, a la atomización y a los elevados costes salariales (Maluquer de Motes, 1985, p. 218). Por su parte, Rosés (2001) achaca a los elevados aranceles la baja eficiencia de la industria algodonera española. Últimamente, Llonch (2004), pp. 128-129, ha vuelto a subrayar el impacto negativo de los costes laborales sobre la competitividad. El VIII Congreso de la Asociación Española de Historia Económica ha dedicado la sesión B4 —coordinada por J. Catalan, J. A. Miranda y R. Ramon-, a la problemática de la industria en el mercado mundial.

Prat y Soler (2002).

Nadal (1975); Sudrià (1999); Nadal y Sudrià (1993).

A diferencia de quienes se centran en el coste de los factores, Anna Carreras señala que el mercado internacional de tejidos de algodón estaba condicionado por la persistencia del antiguo dominio colonial en el mercado de los países ya independientes, la especificidad del comercio intraeuropeo y el peso de la diferenciación del producto como estrategia competitiva (Carreras Marín, 2001a y 2001b). 
la relevancia de las aportaciones, el tema de la productividad es todavía una asignatura pendiente en la historiografía económica española ${ }^{15}$. Un segundo eje de entronque con las líneas recientes de investigación internacional lo proporciona el debate sobre los índices de producción industrial, en general, y de la industria algodonera, en particular. En sus derivaciones más recientes, el debate ha sido revisado en función de las variaciones en la calidad del producto a lo largo del tiempo $^{16}$.

Así pues, las páginas siguientes pretenden aprovechar la ventaja relativa de la historia empresarial, en expresión de Valdaliso (2004), para aportar elementos de respuesta a algunas cuestiones suscitadas en el debate sobre la industria algodonera. Su propósito es comprobar si, entre las diversas estrategias posibles para mejorar la competitividad en el mercado interior, La España Industrial —que representaba, en cierta medida, a un importante sector de la industria algodonera española - tuvo como objetivo aumentar la productividad mediante el cambio tecnológico. La incidencia de esta empresa en la industrialización española, unida a la conservación de su archivo, ha hecho de ella objeto de atención privilegiada por parte de los historiadores ${ }^{17}$. En estas páginas, La España Industrial adquiere la categoría de exponente de una actitud que, si no al conjunto, cuando menos se podría extender al sector más dinámico de la industria algodonera catalana, componente mayoritario de la española.

Los argumentos aquí esgrimidos se sustentan en el procesamiento y elaboración de un ingente cúmulo de datos procedentes de fuentes de la empresa, algunas de ellas escasamente explotadas hasta la fecha. Destacan los Libros de Inventario (que recogen de forma minuciosa los cambios de maquinaria y equipo), los Libros de Semanales, los Estados mensuales, la Correspondencia y el Movimiento Fabril y Mercantil. Los primeros cubren la práctica totalidad del período estudiado, mientras que el último arranca en un momento ya avanzado de la trayectoria de la empresa. Respecto a la estructura del texto, en la primera sección se exponen las características de la opción empresarial representada por La España Industrial, los objetivos básicos que perseguía y la pugna por mantener la competitividad; en la segunda, se describen los ciclos inversores y su concreción en el cambio tecnológico; en la tercera, finalmente, se examinan los efectos sobre la productividad.

15 Es la principal conclusión que se extrae del ejercicio de Carreras (1989), p. 180, y que tan sólo cabría matizar con la nueva versión de Carreras y Tafunell (2005). Una síntesis reciente en Valdaliso (2004), pp. 21-25. Estudio pionero de cita obligada es el de Camps (1995) sobre la formación del mercado de trabajo industrial en España, basado en buena medida en fuentes empresariales.

16 Carreras (1990); Prados (1988); Maluquer de Motes (1994); Sudrià (1983), y Rosés (2004).

17 Sirvan de ejemplos Camps (1995), Ribas (1999) y Gutiérrez (1997). 


\section{La España Industrial}

Durante el primer tercio del siglo XIX logró afianzarse en España una industria algodonera moderna con características similares a las del resto del continente ${ }^{18}$. Ejemplo del nuevo impulso inversor que siguió al final de la I Guerra Carlista, La España Industrial fue fundada en 1847 por un grupo de industriales, banqueros y políticos vertebrado por la familia Muntadas, convencido de la rentabilidad y del porvenir seguro de la industria. Sin duda, la idea inicial surgió del núcleo del Instituto Industrial de España, creado siete años antes a partir de dos entidades preexistentes. De esta manera, se fundía en un proyecto vasto y ambicioso la vieja savia industrialista catalana, representada por los Muntadas — antiguos pelaires de Igualada-, con otras ramas del mundo empresarial y financiero español.

La España Industrial destacó por la cuantía de su capital social, que se elevó a 50 millones de reales. En el accionariado se distinguían tres grupos: fabricantes y comerciantes de Barcelona, capitalistas madrileños dedicados a negocios especulativos y, finalmente, empleados y colaboradores de la empresa ${ }^{19}$. Su primer éxito fue, por tanto, la capacidad de conectar con sectores dispuestos a comprometer sus ahorros en el desarrollo de una industria moderna en España. Ello suponía romper con la localización aplastantemente mayoritaria de la industria algodonera en Cataluña ${ }^{20}$. De hecho, capitalistas de diversas zonas mostraron su interés por sumarse al proyecto $^{21}$. Muy pronto, empero, la crisis económica propinó un golpe importante a las aspiraciones del grupo, que se vio obligado a aparcar sus planes de expansión por el conjunto del país y a confinar su actividad industrial en Barcelona.

La España Industrial aunó el carácter moderno en su doble aspecto formal y técnico. Optó por la modalidad de sociedad anónima y por órganos capaces de llevar el proyecto a buen puerto, a saber, una dirección con amplia libertad de movimiento, encomendada a la familia Muntadas, y una Junta de Gobierno, compuesta por los

18 En aras de la brevedad, señalo tres estudios clásicos y uno que revisa el crecimiento anterior a la década de 1830: Nadal (1975), Maluquer de Motes (1976), y Sánchez Suárez (1989) y (2000).

19 De un total de 25.000 acciones de 2.000 reales tan sólo llegó a suscribirse el 64 por 100, de forma que, en 1852, el capital se redujo a 32 millones de reales. Entre los accionistas de Barcelona, titulares de 4.405 acciones, figuraban algunos pioneros de la industria algodonera y metalúrgica, como Rull, Ramis, Tous o Ascacibar. Pese a que la familia Muntadas, eje del proyecto, recibió 1.632 acciones y constituyó el grupo más fuerte, el núcleo accionarial básico, con 10.095 acciones en su haber, estaba en Madrid. Arxiu Nacional de Catalunya (ANC, en adelante), Fondo La España Industrial (Fondo LEI), Correspondencia expedida, 12/agosto/1847, 26/abril/1847, 1/mayo/1847 y 17/mayo/1847.

20 Estos empresarios se proponían "desarrollar la industria algodonera en sus varios ramos" por toda España; carta al director del Banco de Barcelona, 17/febrero/1847 (ANC, Fondo LEI, Correspondencia recibida).

21 Bofill, Batlle y Cía., a los directores de La España Industrial, Valencia, 5/marzo/1847 (ANC, Fondo LEI, Correspondencia recibida). 
diez socios fundadores, más tarde convertida en Junta Inspectora. Desde el punto de vista técnico, sustituyó la tradicional infraestructura industrial, dispersa y poco eficiente $^{22}$, por un establecimiento movido por la energía más eficaz y equipado mayoritariamente con la maquinaria más avanzada del momento - selfactinas y telares mecánicos-23. Debido a las características del mercado mundial, se trataba sobre todo de equipo inglés, eso sí, adaptado a las condiciones de Cataluña ${ }^{24}$. Merece la pena subrayar, por ejemplo, que se anticipó en seis años a la Fábrica de la Rambla de Vilanova i la Geltrú en la instalación de selfactinas. Al cabo de poco tiempo, la capacidad productiva fue de nuevo ampliada, hasta convertir la fábrica en la mayor de España ${ }^{25}$. Pese a los proyectos de buscar un emplazamiento rural para utilizar la energía hidráulica, las economías de aglomeración ofrecidas por la ciudad de Barcelona aconsejaron localizar en sus inmediaciones la producción, con la consiguiente opción por el carbón como fuente de energía.

Los impulsores de La España Industrial buscaban hacerse un hueco en el mercado interior con un producto competitivo pero sin renunciar a la calidad, estando dispuestos, incluso, a supeditar a ésta la productividad. Por tanto, el éxito dependía, fundamentalmente, de las economías de escala — tanto en la producción como en las condiciones de obtención de la materia prima-y de la buena organización ${ }^{26}$.

Había sido aportada por una de las sociedades fundadoras. Muntadas Hermanos, Copiadores de Cartas, 28/agosto/1848, 4/septiembre/1848, 3/abril/1849 y 22/abril/1850 (Museu d'Estampació de Premià de Mar, MEPM, en adelante).

23 Revista Industrial, marzo de 1858, p. 116. El equipo inicial se compuso de 18.000 husos de selfactina Sharp, 3.000 husos de continua de araña Platt y 500 telares.

24 Para no citar más que un ejemplo, la disposición de la sala de telares fue el resultado del trabajo conjunto del constructor de máquinas Hibbert Platt y del técnico Ángel Martorell, destacado por La España Industrial en Manchester (ANC, Fondo LEI, Correspondencia expedida, 7/octubre/1847). La red de La España Industrial comprendía técnicos como M. de Bergue y J. Barrau, que asesoraron y sirvieron de intermediarios. Martorell seguía de cerca la construcción de los telares Platt, pasaba información sobre formas de fabricación y sugería posibles innovaciones en la maquinaria (ANC, Fondo LEI, Correspondencia expedida, 30/noviembre/1847). Un ejemplo de la voluntad de adaptación a las condiciones climáticas de Cataluña, país más cálido que Inglaterra, fue la aplicación de un dispositivo de alambre en lugar de goma en las mecheras (ANC, Fondo LEI, Correspondencia expedida, 2/septiembre/1847).

25 Hay discrepancias, derivadas sin duda del momento de la observación. Así, en una carta a Heath de Londres figuraban 300 telares (ANC, Fondo LEI, Correspondencia expedida, 13/marzo/1852); la factura de la maquinaria ajustada en Inglaterra recoge 18.036 husos de selfactina Sharp; mientras Gutiérrez (1997), pp. 193-194, da 2.240 husos de continua y 18.336 de selfactina y 500 telares. Entre 1852 y 1853 , se instalaron 34 selfactinas, 423 telares mecánicos, 463 peines, 1 mechera, 1 urdidor, 90 máquinas de plegar, 2 máquinas de bobinar, 1 máquina de torcer y 1.100 lanzaderas mecánicas (ANC, Fondo LEI, Libros de Inventario). En 1865, existían 114 selfactinas con 37.778 husos, 22 continuas de araña con 3.520 husos y 7 mule jennies con 840 husos (Información sobre el derecho diferencial de bandera, tomo 4, p. 11).

26 Al técnico Martorell se le pedía, por ejemplo, que limitase la velocidad de los telares para evitar los defectos (ANC, Fondo LEI, Correspondencia expedida, 30/noviembre/1847). Las grandes fábricas tenían mayor poder negociador para conseguir el algodón en rama a precios más baratos (Tafunell y Castañeda, 1999, p. 993). 


\section{GRÁFICO 1}

PRODUCCIÓN DE HILO Y TEJIDOS EN LA ESPAÑA INDUSTRIAL, 1855-1931

(números índice, base $100=1913$ )

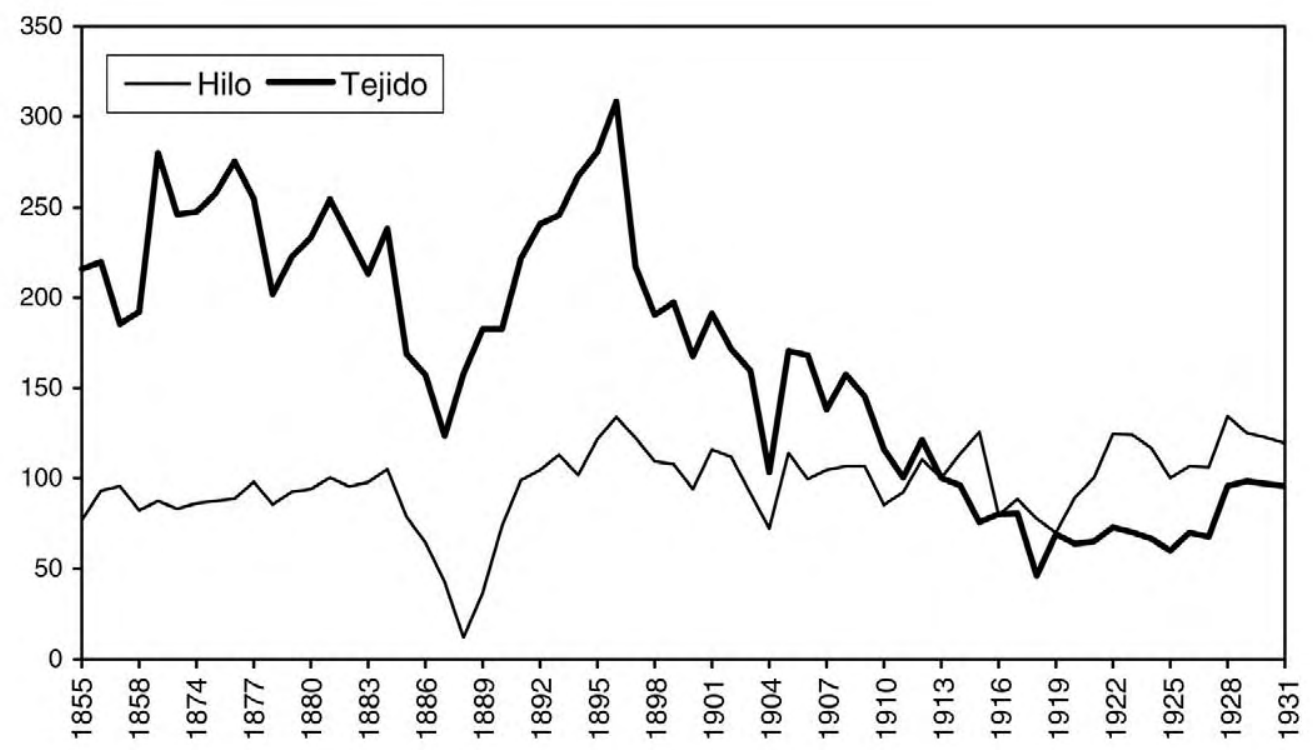

Fuentes: Elaborado a partir de ANC, Fondo LEI, Estats mensuals.

$\mathrm{Al}$ primer reto respondieron con la fábrica de Sants ${ }^{27}$, que al gran tamaño unía un sistema de producción integrado o de ciclo completo. El moderno sistema fabril exigía una producción regular para rentabilizar la inversión. Sin embargo, en una industria volcada hacia un mercado interior caracterizado por una economía básicamente agraria, sometida a la magnitud y ritmo de las cosechas, era lógica cierta inestabilidad de la demanda, que se traducía en incertidumbre, oscilaciones de la producción y modificaciones en el tipo de producto. De hecho, las oscilaciones en la producción fueron una constante en La España Industrial, como muestra claramente el Gráfico 1.

La aparición de organizaciones defensoras de los intereses obreros añadió otro elemento de inestabilidad a la producción. Los grandes conflictos de la década de

Nadal (1975) y (1991). La fábrica de Sants, en las afueras de Barcelona, comenzó a operar de forma gradual: en abril de 1849 funcionaban 14 continuas, 36 selfactinas y 160 telares, entre otros; a finales de mayo, funcionaba ya toda la hilatura; del 23 al 28 de mayo se empezó a estampar; del 7 al 12 de noviembre, a blanquear y del 13 al 18 de febrero de 1854, a teñir. MEPM, Fondo LEI, Copiadores de Cartas, 2/abril/1849 y 21/mayo/1849; ANC, Fondo LEI, Comunicats Setmanals. 
1880, de los inicios del siglo XX y de la primera posguerra mundial, dejaron una profunda huella en la evolución de La España Industrial. El tercer elemento capaz de alterar el régimen productivo fue la innovación tecnológica, que se circunscribió a algunos períodos y se solapó, a veces, con situaciones conflictivas.

La inestabilidad de la demanda y la variabilidad del producto podían ser corregidas mediante mecanismos reguladores. La España Industrial, que, como se ha dicho, había optado por una producción concentrada en fábrica de ciclo completo, elaboraba la inmensa mayoría del hilo destinado a sus propios telares. La producción efectuada fuera de la fábrica suponía una porción minoritaria, y tenía el doble carácter de complemento en tiempos normales y de sustitución en momentos especiales. Las ventas de hilados se situaban casi permanentemente en torno al 20 por 100 de la producción total. En otras palabras, la producción se ajustaba a los pedidos, siendo excepcionales las alteraciones de esta conducta, como sucedió en la década de 1880, en el período posterior a la independencia de las últimas colonias americanas y durante la I Guerra Mundial. El carácter de fábrica integrada daba la posibilidad de adaptarse rápidamente a los cambios en el tipo de producto impuestos por el mercado, debido a la capacidad para obtener de forma inmediata hilo de las características adecuadas a las telas demandadas.

\section{La opción por el riesgo: inversión y cambio tecnológico}

Debido a la necesidad de rendir cuentas ante los titulares de las acciones, el tema de la rentabilidad preocupaba de forma especial a La España Industrial. Ya en 1860, uno de los accionistas se hacía eco de una creencia muy extendida entre los socios de la empresa y el público, según la cual el capital empleado en La España Industrial tenía una rentabilidad inferior al de otras empresas, en contradicción manifiesta con el incremento de productividad que la ciencia económica concedía al aumento del tamaño. Para poder aclarar el asunto, el mencionado accionista reclamaba un estudio escrupuloso orientado a "producir tan barato como el que más y a equipararse al resto en el logro de intereses". Al tiempo, como remedio a las posibles deficiencias, proponía concentrar toda la actividad en la fábrica de Sants, como culminación de un proceso de desalojo de los establecimientos de Sabadell, centro lanero, y Sarrià ${ }^{28}$.

28 Documentos de las juntas generales de accionistas, 5/febrero/1860, MEPM, Fondo LEI. Órganos especializados llamaban la atención sobre la menor rentabilidad — por debajo, incluso, de los valores públicosde La España Industrial y de otras empresas en comparación con las fábricas de Oldham (El Economista Español, julio de 1890,1 , p. 23). 


\section{GRÁFICO 2}

INVERSIÓN POR SECCIONES EN LA ESPAÑA INDUSTRIAL, 1851-1931

(pesetas corrientes)

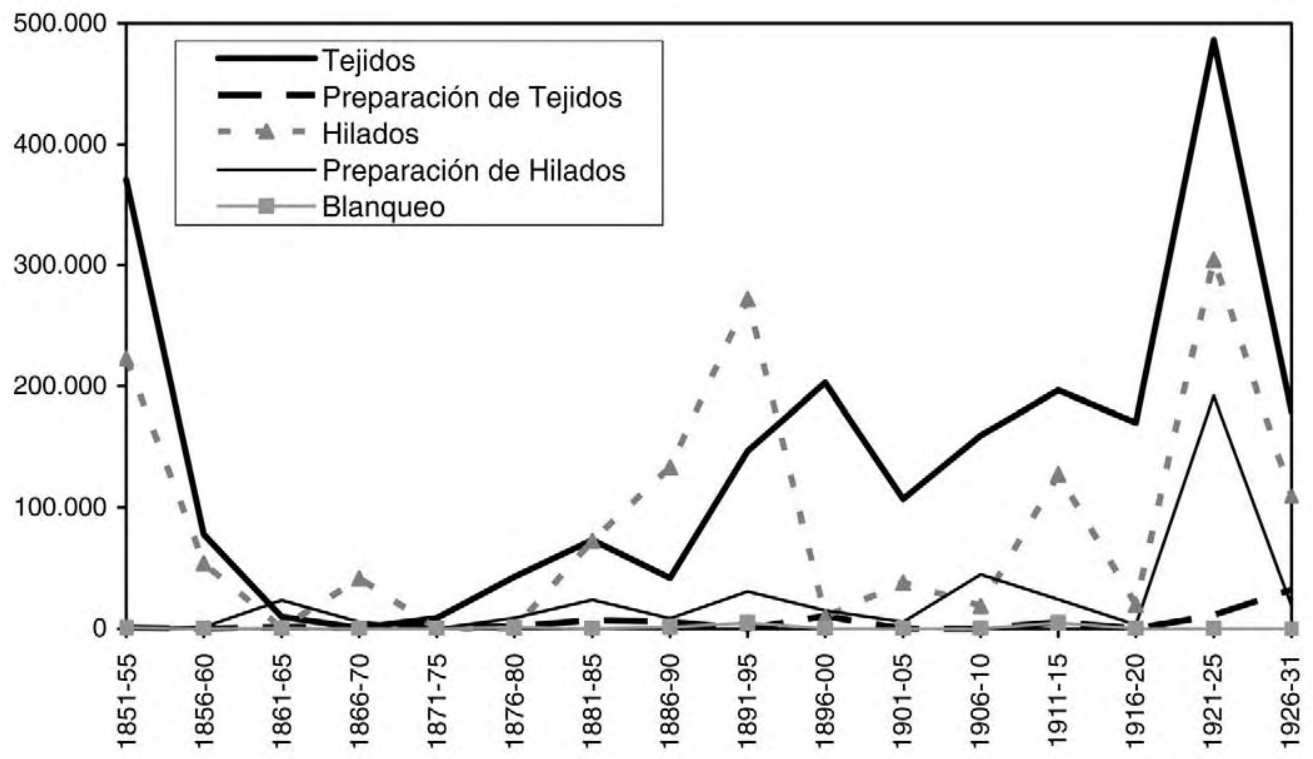

Fuentes: Elaboración a partir de ANC, Fondo LEI, Libros de Inventario.

Gran tamaño y maquinaria moderna exigieron un intenso proceso de formación de capital. Del Gráfico 2, elaborado a partir de los Libros de Inventario ${ }^{29}$, se desprende la existencia de tres ciclos inversores. El primero es prolongación y cierre de la etapa de implantación de la empresa; los otros dos ciclos tienen una amplitud aproximada de treinta años y una intensidad diferente, con oscilaciones muy fuertes. Recogen, por tanto, la primera gran ampliación, la gran transformación de la fábrica a finales del siglo XIX y la remodelación de la década de 1920.

El enorme esfuerzo inversor derivado de los gastos de primer establecimiento ${ }^{30}$ permitió a La España Industrial afrontar en condiciones ventajosas las dificultades durante un largo período y afianzarse en el mercado. Pero en las dos últimas déca-

29 ANC, Fondo LEI. Se ha tenido en cuenta la instalación de máquinas pero no la simple reposición.

30 La empresa valoraba los edificios de hilatura en 1.440.000 reales de vellón; las transmisiones en 374.200 y la maquinaria en 1.982 .300 (ANC, Fondo LEI, Correspondencia expedida, 4/noviembre/1848 y 10/noviembre/1848). 
das del siglo XIX, las condiciones en que se movía tradicionalmente la empresa empezaron a cambiar en profundidad. El gran reto para la industria algodonera de Barcelona y su hinterland del Llano pasó a ser la pérdida de competitividad frente a las fábricas de río, que gozaban de ventajas comparativas en los precios de la mano de obra, la energía y los impuestos. La respuesta que La España Industrial dio a este reto fue el cambio tecnológico para abaratar los costes de producción sin necesidad de cambiar la localización, lo que suponía mantener las economías de aglomeración. Vale la pena subrayar que la opción de La España Industrial por la innovación se apoyó en una utilización constante de recursos propios, que le garantizaron una independencia envidiable y una disminución de los costes financieros ${ }^{31}$.

Cuarenta años de funcionamiento habían hecho envejecer inexorablemente la maquinaria ${ }^{32}$ y ponían a La España Industrial ante el dilema de renovarse o morir. Por otro lado, la capacidad productiva de la industria algodonera española estaba llegando a su cénit, en un contexto mundial de fuerte crecimiento del sector en algunos países periféricos, sobre todo la India y Japón. Se abrió así un período de grandes transformaciones, impulsadas a su vez por una coyuntura de crisis. Veamos, primero, las respuestas comunes que se dieron a las dificultades cuando el final de la euforia de la febre d'or y la persistencia de la inseguridad de los mercados provocaron un doble movimiento de contracción y de fraccionamiento de la demanda ${ }^{33}$. Como primera medida, la empresa redujo, con el cambio tecnológico, los costes y los precios para hacer frente a la agudización de la competencia ${ }^{34}$. La segunda gran línea de actuación fue la innovación en producto para incrementar la penetración en el mercado con artículos de gran aceptación (vichys y pañuelos), dedicando recursos al estudio de sus características y de la maquinaria necesaria para producirlos. En tercer lugar, se buscaron economías de escala aumentando la producción, incluso a base de géneros destinados al mercado colonial, que, sin dejar grandes beneficios, permitieran reducir los costes unitarios. Finalmente, la reducción parcial del trabajo permitió paliar las dificultades, como ocurrió en las últimas semanas de 1884 .

31 ANC, Fondo LEI, Memorias de la Junta de Accionistas; Ribas (1999). Según Y. Blasco (comunicación personal), La España Industrial figuraba en posiciones muy bajas entre los beneficiarios de créditos del Banco de Barcelona.

32 La empresa reconocía que la maquinaria no estaba, desde hacía años, a la "altura de los adelantos industriales" (ANC, Fondo LEI, Memorias de la Dirección).

33 La dirección señalaba como causas la falta de pedidos, sobre todo en Andalucía, la paralización de las ventas y la acumulación de stocks en los almacenes de Cataluña. A ello se añadía la perspectiva de los tratados con Inglaterra. Algunos mercados, como el de Valencia, se vieron severamente castigados por una epidemia, que sumió a la población en la alarma y el pánico (ANC, Fondo LEI, Correspondencia recibida).

34 En concreto, reformó el laboratorio químico, introdujo las primeras continuas de anillo y llevó a cabo algunos cambios menores (Junta de 1884, MEPM y ANC, Fondo LEI, Libros de Inventario). 
La depresión finisecular endureció las condiciones habituales en que se movía la industria algodonera catalana. En efecto, a las dificultades derivadas de la permanente estrechez del mercado interior se sumaron ahora la reducción de la capacidad adquisitiva de los clientes de zonas trigueras (provocada por la competencia del cereal extranjero) y el aumento de la importación de tejidos. En 1886, cerraron algunas fábricas y se redujo el trabajo en otras, hechos que, a su vez, ocasionaron despidos y emigración. El impacto negativo se dejó notar especialmente en Barcelona, donde, además, se sucedieron huelgas con gran frecuencia, sin que nuevas oportunidades de empleo, como las deparadas por la preparación de la Exposición Universal, fueran suficientes para acabar con el paro.

La crisis agravó los problemas que arrastraba la industria algodonera, aquejada de elevados costes de la materia prima y de los salarios ${ }^{35}$. La imperiosa necesidad de abaratar los costes para hacer frente a la agudización de la competencia interna empujó a un sector crecientemente importante de los industriales catalanes por el camino de la innovación tecnológica. Su expresión más vistosa en la fabricación de hilo era la continua de anillos, hasta entonces escasamente competitiva pero que se había convertido en muy productiva y fácil de manejar ${ }^{36}$. Evidentemente, la enorme variedad de la estructura empresarial y productiva hizo que las formas de adopción de esa máquina fueran rápidas en unos casos y graduales en otros. Así pues, las continuas se introdujeron en fábricas de situación geográfica, tamaño y estructura de mano de obra diversos. Empezaron a ser tendencialmente significativas en las nuevas inversiones desde fechas relativamente tempranas, pero hasta los primeros años del siglo XX no se convirtieron en una opción permanente y mayoritaria. Con ello, se alteró la estructura técnica del sector en favor de la continua que, en vísperas de la I Guerra Mundial, totalizaba casi las dos terceras partes de la maquinaria instala$\mathrm{da}^{37}$. La comparación europea situaba la opción catalana entre la pauta italiana, por un lado, y la franco-alemana, por otro.

En el proceso de cambio provocado por la crisis, no todas las empresas corrieron idéntica suerte. Algunas de las pioneras en la introducción de las continuas de anillo se vieron abocadas al cierre, como sucedió con Batlló y Batlló, una gran empresa barcelonesa de ciclo completo. Otras, entre ellas la fábrica Güell, dispuestas a mantener su statu quo tecnológico pero preocupadas por la llamada "reforma del trabajo", se estrellaron contra un movimiento obrero potente ${ }^{38}$, viéndose obligadas a

\footnotetext{
35 Éstos últimos se debían, en parte, al excesivo número de trabajadores por máquina: 3,29 obreros por 1.000 husos en Gran Bretaña; 8,94 en Francia y 11,93 en España (Calvo, 1986, pp. 41 y ss).

Calvo (1999).

Nadal (1991), Saxonhouse y Wright (2004).

Calvo (1990), p. 158.
} 
abandonar el emplazamiento urbano y a buscar mano de obra más dócil en la zona rural cercana a Barcelona. Finalmente, hubo otras que tuvieron éxito en su opción por modernizarse y por mantener el carácter urbano. Alineándose entre estas últimas, La España Industrial, sin ser pionera en la introducción de la continua de anillos, se anticipó en varios años al gran movimiento de adopción recién descrito. Al romper con una relativa estabilidad tecnológica, largo tiempo mantenida en la sección de hilatura, perseguía un doble objetivo: economizar mano de obra y combustible. Su preocupación se centraba en el mercado interior, pero tampoco estaban ausentes del todo el mercado colonial y algunos mercados próximos, como el portugués.

La obsesión por reducir costes laborales chocó con los obreros, que respondieron con una larga huelga a la pretensión patronal de suprimir el pago de los días festivos entre semana ${ }^{39}$. La empresa trató de paliar los efectos negativos de la huelga trasladando a los locales de Barcelona máquinas de pintar en desuso. Pero el persistente decaimiento del mercado obligó a reajustar el trabajo a las necesidades del consumo reduciendo el abanico de productos y el volumen de género estampado.

La persistencia de la crisis, junto con la atonía del consumo, de un lado, y la conflictividad, de otro, se combinaron para impulsar la modernización casi total de la maquinaria en La España Industrial, que se llevó a cabo sólo tras vencer la feroz resistencia opuesta por un sector del accionariado. Al tanto de las nuevas exigencias, el director de la empresa había presentado un plan razonado de renovación parcial de la maquinaria que afectaba, de momento, a toda la sección de hilados ${ }^{40}$. Pero el proyecto chocó con la oposición de la Junta de Inspección, partidaria de una reforma paulatina y parcial que evitara un desembolso brusco ${ }^{41}$. Los adversarios de la reforma la consideraban inoportuna si no atacaba el principal problema de la empresa, la falta de competitividad de sus productos en relación a las fábricas de río. Por tanto, la Junta de Inspección perseguía como objetivo esencial la búsqueda de competitividad, admitía como posible remedio una reforma parcial de la maquinaria y creía factible un traslado de la producción a la montaña para beneficiarse de mejores condiciones respecto a la energía, los impuestos y el precio de la mano de obra. La división ante el plan de la dirección se trasladó al accionariado, llegando a oírse opiniones que desautorizaban a Matías Muntadas y hasta algunas que pedían insistentemente la liquidación de la sociedad. Finalmente, el plan del gerente se impuso

\footnotetext{
39 En algunas secciones, la huelga desembocó en cierre empresarial y paralización prolongada de la producción. Tras quince semanas, el conflicto finalizó con un acuerdo que obligaba a la empresa a abonar los días festivos a cambio de que los obreros recuperaran las horas a lo largo del año. Carta al Gobernador civil de Barcelona, 5/febrero/1887, ANC, Fondo LEI, Correspondencia expedida; MEPM, Fondo LEI, Documentos de las Juntas generales de accionistas de La España Industrial.

$40 \quad$ Muntadas (1887).

41 Junta general de accionistas (1888), ANC, Fondo LEI.
} 
y la Junta de Inspección se vio obligada a dimitir. Las últimas palabras de Muntadas en su intervención ante los accionistas, a finales de agosto de 1888, fueron para remachar los principios sobre los que se asentaba su actuación: prudencia, lealtad y constancia.

La remodelación, que afectó a las secciones de preparación, hilados, tejidos y acabados, supuso en unos casos la modificación parcial del equipo y, en otros, la ampliación e, incluso, nuevas inversiones para sustituir las máquinas existentes (véase el Gráfico 2). Efectivamente, en la primera sección de las aludidas se modificaron las cardas, se renovó buena parte de las mecheras y se instalaron cinco manuales, así como dos batanes con aparato automático para las telas. La sección de hilados se equipó con 21.288 nuevos husos de continua. En la de tejidos, 400 telares nuevos pero no automáticos y 500 reformados sustituyeron al millar preexistente. De no poca importancia fueron las calderas y sistemas diversos instalados en las secciones de acabados, puesto que permitían economizar agua y vapor, así como productos químicos, generalmente de elevado precio. Convendría no olvidar las transformaciones que afectaban a la manipulación de los productos, a la racionalización del espacio productivo y al sistema energético. Respectivamente, consistieron en la instalación de un montacargas en la sección de hilados, en la concentración de la producción de tejidos en una misma cuadra, en el alumbrado por gas de procedencia externa y en la centralización de la producción de fuerza motriz gracias a una gran máquina de vapor de 750 caballos, cuya eficiencia mejoró gracias a un sistema de transmisiones por cable. Conviene destacar que la reforma no estableció vinculaciones onerosas con los mercados de capital, ya que su coste fue saldado con recursos propios $^{42}$. Por otra parte, se acentuó la concentración de la actividad en Sants, al trasladar allí la subsección de aprestos que funcionaba en los locales de Barcelona ${ }^{43}$.

El cambio tecnológico abrió un lapso transitorio en el que se impusieron diversos reajustes. Con buena parte de la fábrica paralizada, la producción se resintió y hubo que aumentar las compras de tejidos crudos sin blanquear (empesas) para hacer frente a una demanda en aumento ${ }^{44}$. En poco tiempo, la reforma reforzó el peso de la sección de hilados y tejidos en la composición técnica del capital de la fábrica. Los efectos positivos se manifestaron de modo inmediato en forma de reducción en una cuarta parte del coste de producción y de obtención de beneficios. Asimismo, la Bolsa reaccionó favorablemente y las acciones de La España Industrial subieron.

42

El coste ascendía a 1.092.000 pesetas (Memoria de la Dirección, 1 de febrero de 1891, ANC, Fondo LEI). Se vendieron solares en Sants y se acensuaron otros. Un préstamo concertado con el Banco Hipotecario de España no llegó a utilizarse (Memoria de la Dirección, 26/agosto/1888 y 30/agosto/1891, ANC, Fondo LEI).

43 Memoria de 24/febrero/1889, ANC, Fondo LEI.

44 Debido, según la gerencia, a la "buena estampación, brillante permanencia del colorido, delicado gusto y perfecto acabado" (Memoria de la Dirección, 26/agosto/1888, ANC, Fondo LEI). 
Tamaña transformación se acompañó de una reestructuración drástica del empleo tras la huelga ya mencionada. En su vertiente cuantitativa, el recorte de plantilla, de un 42 por 100, supuso una fuerte disminución de los gastos. Desde el punto de vista cualitativo, la introducción de las continuas de anillo abrió la posibilidad de recalificar la mano de obra y cambiar el sistema de retribución, sustituyendo obreras adultas pagadas a destajo por jóvenes a jornal ${ }^{45}$. A ello habría que añadir el ahorro en combustible y reparaciones, así como la mayor perfección del trabajo fabril ${ }^{46}$.

Es natural preguntarse por los objetivos finales que perseguía la reforma que hemos descrito. Desde el punto de vista de la dirección de la fábrica, se trataba, ni más ni menos, de — utilizando sus propios términos— "dar vida a un cadáver". En la medida en que lo logrado puede ser la expresión visible de los objetivos marcados, cabe decir que la reforma buscaba reducir los costes laborales, mediante el recorte de la plantilla y la supresión de las primas, y, a la vez, economizar energía. Por descontado, la posición de la empresa en el mercado interior estaba en juego, pero había algo más. Según reconocía la dirección, en una coyuntura internacional favorable, léase el conflicto anglo-portugués, también se buscaba un hueco en el mercado exterior para los tejidos de La España Industrial. Ello explica que, pese a los altos derechos arancelarios del país vecino, la empresa destinase medios humanos para acceder al "no despreciable mercado de Portugal", enviando un viajante a la frontera y a Lisboa ${ }^{47}$.

El gran esfuerzo desplegado en diversas secciones debía extenderse a otras para colmar las expectativas. La fase final de la reforma, llevada a cabo en 1900, se orientó a la reducción de costes laborales y energéticos en el ramo del agua, a la vez que a la innovación en producto. Todo ello se logró con la supresión del trabajo nocturno, la instalación del alumbrado eléctrico de producción propia, la automatización de la elaboración de los colores, diversos ajustes en los chapones para evitar pérdidas en el lavado y la mecanización de la labor de mercerizar. También se mecanizaron, al menos en parte, las operaciones de oxidado y secado de géneros especiales, así como el escurrido de piezas lavadas para facilitar el secado, con el consiguiente ahorro de carbón. Nuevos cambios afectaron a las fases iniciales del proceso de elaboración del

45 Borderías (en prensa). Sobre la existencia de modalidades de empleo diferentes y el predominio de la mano de obra femenina en Reus, Garcia Balañà (2004), p. 453 y ss. Sobre la resistencia obrera a la introducción de las continuas y el aumento de la conflictividad obrera, véase Smith (1991). Sobre la reforma y sus efectos sociales, Enrech (1996-97), (1998), (2003a) y (2003b).

46 En los tejidos, estudiados aquí con menor detalle, M. Muntadas pretendía duplicar la producción por tejedor a cambio de aumentar el 20 por 100 del sueldo (Memoria de la Dirección, 30/agosto/1891, ANC, Fondo LEI, Datos de la producción, p. 146).

47 Memoria de la Dirección, 23/febrero/1890, ANC, Fondo LEI. 
algodón $^{48}$. Tras una fase de crisis y conflicto ${ }^{49}$, la I Guerra Mundial forzó un nuevo ciclo inversor que culminaría en los años veinte. El esfuerzo se centró especialmente en la ampliación y perfeccionamiento de la sección de tejidos con nuevos telares para panas, la mayoría provistos de mecanismos especiales (máquinas tap), cortadoras que mecanizaban una de las operaciones más caras y humidificadores para las telas ${ }^{50}$.

Uno de los cambios más espectaculares en el conjunto de la fábrica fue la sustitución del vapor por la electricidad, ahora como fuerza motriz y de procedencia externa ${ }^{51}$. Aunque en la memoria anual el hecho queda recogido sin ningún énfasis, años después M. Muntadas le daría el máximo relieve y lo calificaría de "otra transformación trascendental más importante aún si cabe que las anteriores, y desde luego tan oportuna y afortunada como ellas" ${ }^{\prime 2}$. Idéntica orientación de ahorro energético presidió, en pleno conflicto mundial, la automatización de la carga de las calderas de vapor, capaz de ahorrar la quinta parte del carbón necesario para su funcionamiento ${ }^{53}$. Poco después, en 1923, la estructura de costes energéticos, dominada por el carbón, varió sustancialmente, ya que el 86 por 100 de la energía absorbida por las operaciones de hilar y tejer el algodón era de procedencia eléctrica, porcentaje que se reducía drásticamente en el ramo del agua ${ }^{54}$.

\section{El aumento de la productividad}

La productividad, uno de los indicadores más claros de la eficiencia y del crecimiento económico, mide las relaciones entre una unidad de producción y la cantidad de input que se necesita para producirla ${ }^{55}$. Componentes de la productividad son la tecnología,

Memoria de la Dirección, 10/febrero/1901, ANC, Fondo LEI. En 1912-13, se sustituyeron las 85 cardas viejas por 14 nuevas (Memorias, 16/febrero/1913 y 15/febrero/1914, ANC, Fondo LEI). Mercerizar consistía en tratar las telas con procedimientos químicos para darles apariencia de seda. Los obreros de La España Industrial tuvieron una alta participación en la huelga general del textil de 1913 (Instituto de Reformas Sociales, 1914, p. 467).

50 Otras grandes empresas del sector, como C. A. Hilaturas Fabra y Coats, no solamente ampliaron sus instalaciones sino que, además, se vieron inmersas en un proceso de concentración importante, absorbiendo los negocios de otras empresas —en este caso, Manufacturas de Algodón Reunidas e Hilanderías Planas-, (C. A. Hilaturas Fabra y Coats, Memorias de la Dirección, 1924 y 1920).

51 Se instalaron 60 electromotores con 1.700 caballos (Calvo, 1986, p. 41 y ss.). Como quedó dicho, el alumbrado eléctrico se había introducido anteriormente en varias secciones y talleres de la fábrica.

52 Memorias de la Dirección, 1913 y 1922, ANC, Fondo LEI. En la segunda fecha, Muntadas revisaba los grandes momentos de su gerencia. En la hilatura, por ejemplo, la electrificación permitía una velocidad variable en las continuas de anillo, lo que reducía las roturas de hilos (may, 1924, p. 253). 


\section{GRÁFICO 3}

RENTABILIDAD DEL TRABAJO EN LA ESPAÑA INDUSTRIAL, 1890-1934

(beneficios/salarios en pesetas corrientes, en porcentaje)

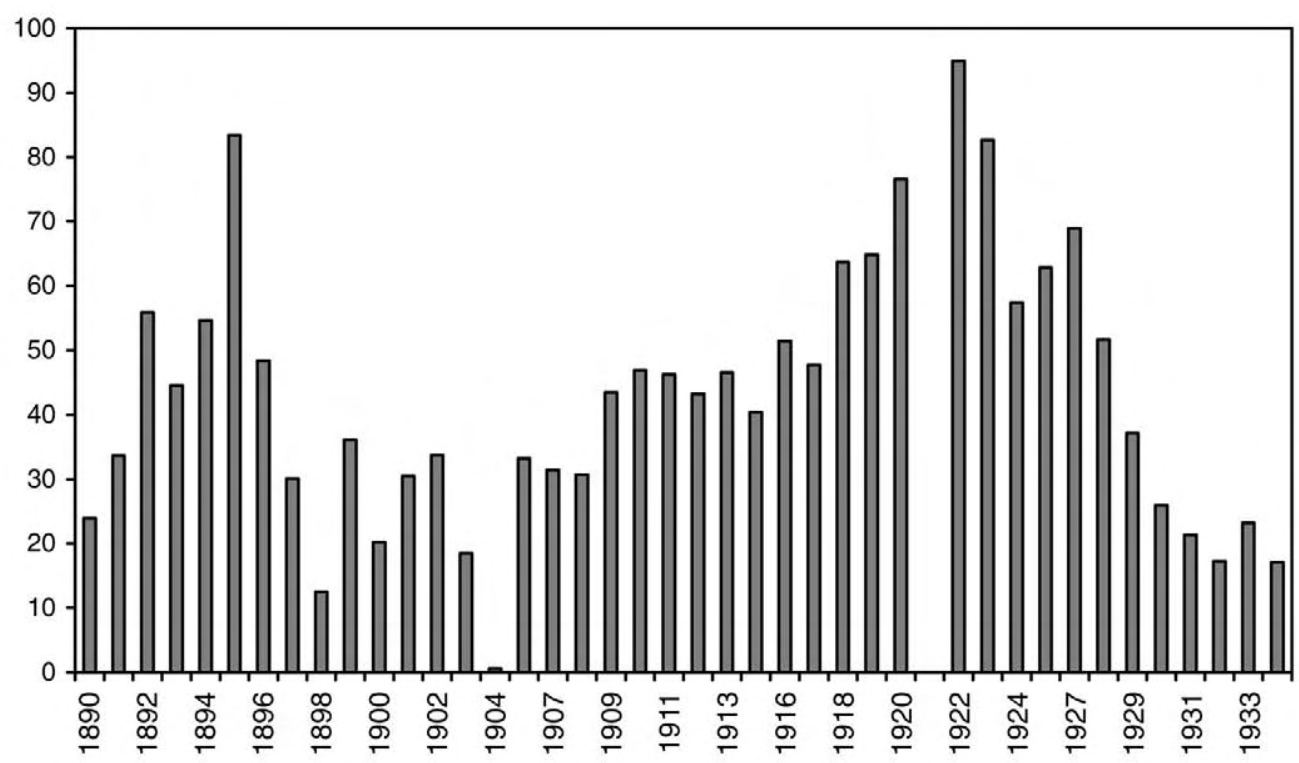

Fuente: Elaboración a partir de ANC, Fondo LEI, Movimiento Fabril y mercantil.

las economías de escala, y los cambios en la cualificación de la fuerza de trabajo y en la organización de la producción ${ }^{56}$. En el caso que nos ocupa, el cambio tecnológico propició un aumento importante de la productividad del trabajo y una reducción de los costes salariales, aspectos estrechamente relacionados con la competitividad. Específicamente, los costes salariales tienen un peso decisivo en la estructura de costes (en torno a la cuarta o quinta parte de los costes totales en los tipos de hilos más comunes).

Empecemos por realizar una aproximación general a la evolución de la rentabilidad del trabajo y del capital en la época posterior al gran cambio tecnológico. El Gráfico 3, elaborado con datos preparados por la gerencia de La España Industrial ${ }^{57}$, permite comprobar que las innovaciones técnicas en la hilatura provocaron un incremento de la rentabilidad, medida aquí por la relación entre beneficios e importe de

$\begin{array}{ll}56 & \text { Jablonsky (1995), p. } 29 . \\ 57 & \text { Movimiento fabril y mercantil 1890-1931, ANC, Fondo LEI. }\end{array}$ 
semanales en pesetas corrientes. Así pues, la tendencia al alza de la rentabilidad del trabajo fue más clara tras la Semana Trágica y se acentuó durante el ciclo expansivo de la I Guerra Mundial, coincidiendo con la electrificación de la fábrica. Pero no fue duradera, cayendo la productividad en la década de 1920 hasta situarse en niveles semejantes a los de comienzos de siglo. Esto quiere decir que el gran esfuerzo inversor de la década, concentrado sobre todo en las secciones de preparación de hilados, hilados y preparación de tejidos, fue contrarrestado por factores que afectaron negativamente a los rendimientos del trabajo. Llama la atención que el movimiento descrito coincida a grandes rasgos con la evolución de la rentabilidad del capital, entendida como la relación entre beneficios y recursos propios ${ }^{58}$.

Una segunda aproximación, limitada a la hilatura, se sustenta en un trabajo más de base a partir de los Estados mensuales y de los Libros de Semanales. Los primeros muestran que el gran esfuerzo inversor del inicio, traducido en la adopción de las máquinas más avanzadas del momento, dio como resultado una productividad sin duda comparativamente elevada pero con claros signos de estancamiento. Dejando de lado el trabajo en las escasas y obsoletas continuas de araña, las obreras ocupadas en las selfactinas, máquinas aplastantemente mayoritarias en la fábrica, tuvieron una productividad relativamente estancada hasta 1882. El cambio tecnológico quebró esta tendencia, puesto que las continuas de anillo permitieron duplicar la productividad por obrera de la fábrica de Sants, como muestra claramente el Gráfico 4 y corrobora el ejercicio posterior a partir de los Libros de Semanales. Conviene resaltar, además, que esta productividad más elevada se mantuvo, aunque no sin fuertes altibajos. Salvo en los años que podríamos calificar de ensayo, la productividad por trabajadora en la hilatura de La España Industrial experimentó un crecimiento espectacular a partir de 1888, coincidiendo con la adopción de las continuas de anillo. Esta vez, los efectos de las innovaciones fueron positivos en términos de productividad a muy largo plazo, puesto que entre 1888 y 1930 la productividad del trabajo se situó netamente por encima del nivel precedente. Cierto es que los elevados niveles de productividad alcanzados en la primera década que siguió al cambio no se mantuvieron a continuación y que la productividad por obrera declinó. Pero superado este período, a la vez crítico y conflictivo, la productividad volvió a crecer con fuerza, hecho que es perfectamente visible si se considera la productividad por obrera-hora, una medida más real, ya que tiene en cuenta las variaciones que hubo en la jornada de trabajo ${ }^{59}$.

Ribas (1999), pp. 1.154-1.155 y 1.158-1.159. Los habituales porcentajes del 5-10 por 100 se dispararon en la coyuntura bélica hasta el 35 por 100.

59

De 66 horas semanales en 1870-1912; a 62 en 1912-1919 y a 48 en 1919-1931 (La España Industrial, Información a la Cámara Oficial de Industria de Barcelona, 1930, Archivo de la Cámara de Comercio, 1, 110-8). Los especialistas están divididos a la hora de expresar la medida de la productividad, ya que unos se inclinan por hacerlo en valor y otros en unidades físicas. Aquí se adopta la segunda opción debido a la imposibilidad de conocer el precio de todos los tipos de hilo. El crecimiento de la productividad del trabajo en La España Industrial contrasta con el retroceso en el conjunto de la industria (Carreras y Tafunell, 2005, pp. 359-360) 


\section{GRÁFICO 4}

PRODUCTIVIDAD DEL TRABAJO EN LA ESPAÑA INDUSTRIAL, 1855-1931

(producción por obrera efectiva)

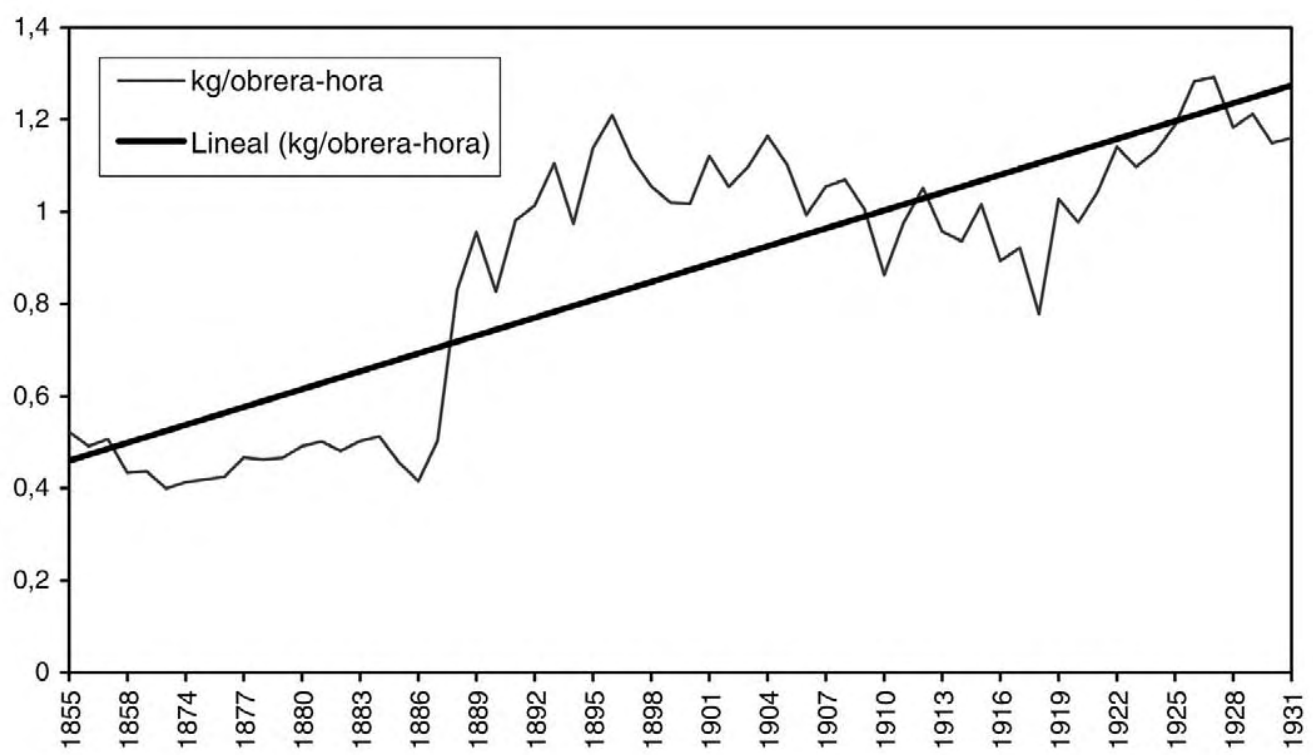

Fuente: Elaboración a partir de ANC, Fondo LEI, Estats Mensuals. No se incluyen las tareas de preparación

Al tratarse de una empresa de ciclo completo, el aumento del rendimiento en el producto intermedio, el hilo, repercutió favorablemente en el coste del producto final, el tejido. Además, la productividad de las restantes secciones también mejoró a partir del cambio técnico, con la consecuente reducción de los costes del tejido. Nadal y Sudrià han demostrado que, luego del espectacular sobresalto provocado por el episodio del "hambre de algodón", los precios del tejido fabricado en La Espa$\tilde{n} a$ Industrial declinaron de forma casi constante hasta finales del siglo XIX ${ }^{60}$. Eso quiere decir que la reforma de la hilatura reforzó una tendencia a la baja que llevaba tiempo manifestándose.

Se podría objetar, con razón, que lo anterior cae en uno de los errores señalados al principio de este artículo, al olvidar que el producto (hilo o tela) no es homogéneo. Conviene, pues, explicar de forma más afinada el comportamiento de la productivi- 
dad del trabajo. Para ello hay que tener en cuenta las dos grandes variedades de hilo - urdimbre y trama - y su calidad, expresada por una escala numérica creciente conforme aumenta la finura. Está claro que la composición del producto influye poderosamente en el volumen de producción. Si se comparan los índices de la finura media del hilo producido y la productividad del trabajo, se observa que existe una relación inversa, si bien no constante, entre ambas variables ${ }^{61}$. Luego la finura del hilo es un elemento relevante pero no único de la productividad. Por tanto, hay que extender la explicación de las variaciones de la productividad a otros factores. Además de la estrategia de diferenciación de producto, existen tres componentes que influyen decisivamente en la productividad: la división técnica del trabajo, la experiencia y el cambio tecnológico. Aquí solamente se considera el tercero desde una aproximación diferente a la anterior, es decir incorporando el tipo de producto a la expresión de la media de la productividad. Pasamos, pues, a analizar la productividad del trabajo según el tipo de máquina, señalando si se trata de trama o de urdimbre en los grupos de numeración de hilo escogidos. En La España Industrial existieron variaciones importantes en la composición del hilo producido y lo mismo puede decirse de los tejidos. Las selfactinas, altamente versátiles, producían una gama más amplia de hilos, mayoritariamente de mediano grosor y tendencialmente cada vez más grueso. Con las continuas de anillo, menos versátiles, disminuyó la gama de hilos producidos.

Un aumento en la finura del hilo y en la calidad de los tejidos implicaba mayor tiempo en la elaboración y mayor salario por unidad de producto. Según los cálculos de la gerencia, en la sección de preparación de hilo la producción de mecha de las máquinas entrefinas disminuía hasta el 36 por 100 por cada número adicional de finura de hilo. Por urdir hilo del número 30 en continuas de anillo se pagaba un 70 por 100 más que por la misma operación con hilo del número 12. La producción por telar dedicado a telas de calidad no llegaba al 20 por 100 de lo que producía un telar empleado en artículos bastos ${ }^{62}$. Evidentemente, la estructura de costes no podía por menos que reflejar las diferencias existentes en las características de los productos. Así, el coste por gastos generales y por color en la fabricación de dos artículos seleccionados podía variar hasta un 70 por 100 e incluso más en la operación de aprestar percalina lisa y damasco ancho ${ }^{63}$.

\footnotetext{
61 Un análisis más detenido del tema en Calvo (2004).

62 Las telas de calidad se refieren en concreto al molesquín y a los artículos inferiores al dril de segunda (ANC, Fondo LEI, Datos de la producción, p. 21).

63 Se trata de la percalina lisa y el molesquín, ya citado como artículo de calidad (ANC, Fondo LEI, Datos de la producción, pp. 56 y 138).
} 


\section{GRÁFICO 5}

PRODUCTIVIDAD DEL TRABAJO EN LAS CONTINUAS DE LA ESPAÑA INDUSTRIAL, 1888-1930

(hilos gruesos —urdimbre, 15-24,6-, producción por obrera efectiva)

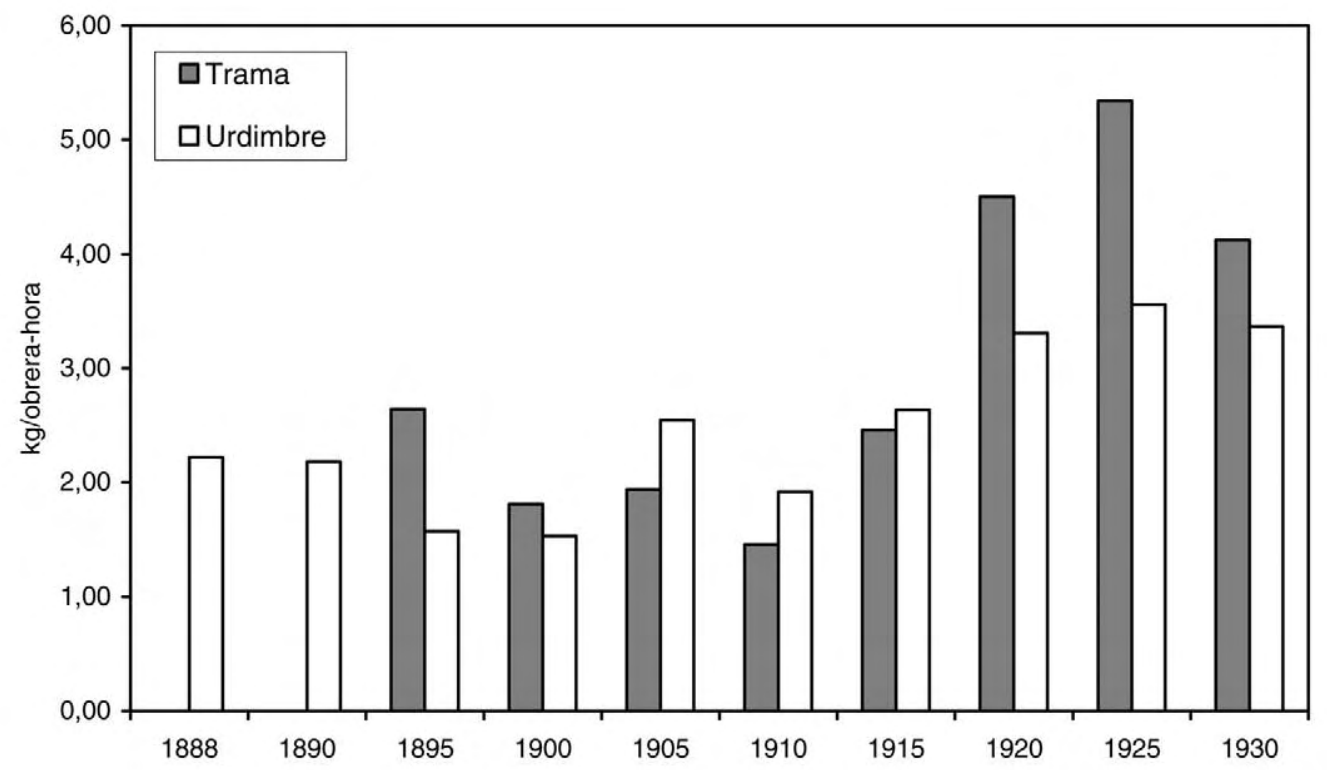

Fuente: Elaboración a partir de ANC, Fondo LEI, Libros de Semanales

Tal y como muestra el Gráfico 5, en la producción de género basto, urdimbre y trama de los números 15-24,6, durante el breve espacio temporal en que coincidieron, la continua de anillo arrancó con una productividad inferior a la que había alcanzado la selfactina, mas la situación se invirtió con el tiempo. En la producción de género medio-bajo, la continua tuvo generalmente una productividad más elevada que su predecesora (Gráfico 6), pero a partir del número 32, el aumento de productividad de las continuas en la fabricación de hilo más fino era muy reducido. Lo que no admite duda es que la continua de anillos resolvió satisfactoriamente los problemas que venía arrastrando la selfactina en la producción de urdimbre desde la década de 1870.

Antes de acabar, se impone una breve referencia a los costes laborales en una empresa cuya práctica se basó en el recurso absoluto a la mano de obra femenina en la fabricación de hilo. Más arriba se ha descrito la opción tecnológica, que entrañaba una planificación cuidadosa de cada pormenor, reflejo de un conocimiento exacto de las condiciones de la producción. Entre los objetivos esenciales, La España Industrial se marcó la reducción de costes, como lo demuestran diversos ejemplos. Uno de ellos 


\section{GRÁFICO 6}

PRODUCTIVIDAD DEL TRABAJO EN LA ESPAÑA INDUSTRIAL, 1855-1930

(hilos medio-bajos —urdimbre, 25-31—, producción por obrera efectiva)

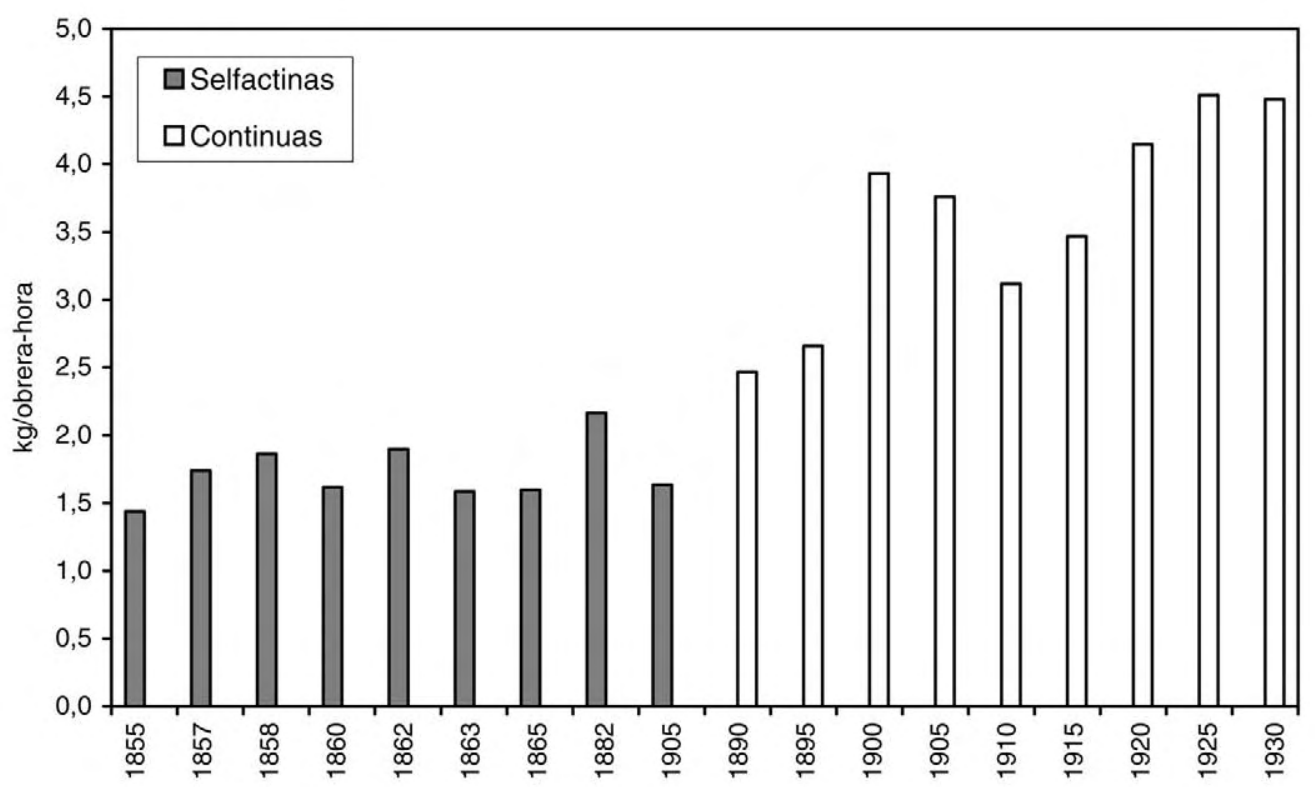

Fuente: Elaboración a partir de ANC, Fondo LEI, Libros de Semanales.

es la petición de poner ruedas de fricción a las cardas para poder accionarlas o pararlas todas simultáneamente, así como ponerlas en marcha gradualmente, con el objetivo de ahorrar tiempo y materia prima ${ }^{64}$. El segundo, y más significativo, se encuentra en la elección de máquinas y en el recurso al trabajo de mujeres jóvenes para recortar costes salariales, aspecto que La España Industrial convirtió en una de sus características diferenciales ${ }^{65}$.

Carta a Schlumberger, 18/agosto/1847, ANC, Fondo LEI, Correspondencia expedida. Aun reconociendo su relevancia, un estudio específico sobre la estructura de costes queda para un futuro artículo.

Borderías (en prensa). Queda para trabajos ulteriores el análisis de los costes laborales unitarios, aspecto que cuenta con la contribución esencial de Camps (1995), pp. 228-229, quien subraya el recurso intensivo al trabajo no cualificado e infantil. Las selfactinas eran más pequeñas en La España Industrial que en la Fábrica de la Rambla de Vilanova, por ejemplo (320-348 husos en un caso frente a 412-452 en el otro). En 1853, la Fábrica de la Rambla tenía ocho continuas Higgins de 253 husos, cinco selfactinas de 412 husos y seis de 452 husos (comunicación oral de R. Soler y Soler, 1999). El 92 por 100 de la mano de obra de la sección de hilatura se componía de mujeres y niñas (Información sobre derecho diferencial de bandera, 1867, p. 14) 


\section{Conclusión}

En suma, las páginas anteriores suponen una apuesta decidida por la historia empresarial como vía para esclarecer aspectos cruciales de la historia económica no suficientemente conocidos a nivel agregado. En ese sentido, se han explorado las relaciones entre productividad y cambio tecnológico en el largo plazo. Para ello se ha estudiado, como representativa del comportamiento del sector, a $\mathrm{La}$ España Industrial, una empresa algodonera de gran tamaño, de ciclo completo (como buena parte del ramo) y moderna en su aspecto formal y tecnológico. Como aportación empírica fundamental, se han construido series largas de producción, inversión y productividad. Como aportación metodológica, se han seguido las tendencias más novedosas, insistiendo en la necesidad de tener en cuenta la uniformidad del producto para salvar las distorsiones que provocan en las series de productividad los importantes cambios en la composición del mismo acaecidos a lo largo del período. Como medida de la productividad se ha tomado la productividad del trabajo, poniendo cuidado en reflejar las variaciones de la jornada laboral. El cambio tecnológico ha recibido a la vez tratamiento cuantitativo, a través de la inversión, y cualitativo, mediante la descripción de los componentes técnicos, casi siempre maquinaria transferida del extranjero y adaptada por personal autóctono.

La perspectiva adoptada - junto a la calidad de las fuentes- aporta elementos destacados al esclarecimiento de aspectos todavía poco conocidos del sector algodonero, pese a los indudables avances acaecidos. Se ha visto, por ejemplo, qué tipo de reajustes imponía la incertidumbre sobre cambios de la demanda y de la coyuntura en una situación de competencia perfecta. Las evidencias ofrecidas ilustran la complejidad de las estrategias aplicadas por las empresas, que, aun cobijadas bajo el proteccionismo, debían afrontar una fuerte competencia interna y no tenían garantizada la supervivencia. Muestran, también, que sólo una parte de las mejoras de la productividad se explican por alteraciones en la composición del producto. El cambio tecnológico descrito aquí con cierta parsimonia, aparece como una pieza clave en una compleja estrategia de reducción de costes, que permitió a algunas empresas afrontar en condiciones ventajosas la pugna por el mercado interior.

Finalmente, lejos de agotar la problemática abordada, el estudio plantea cuestiones fuertemente debatidas en la historia empresarial, entre las que figura como más destacada la que se refiere a la relación entre la forma de la empresa y el comportamiento inversor. En una situación de separación de la propiedad y la gestión, característica de la empresa moderna, la oposición de los propietarios al cambio radical propuesto por la gerencia arroja, cuando menos, alguna duda sobre el automatismo del binomio sociedad anónima-propensión a la inversión. Es cierto 
que, en muchos aspectos, La España Industrial es un caso absolutamente excepcional, pero no lo es respecto del que se estudia aquí, puesto que el mismo camino innovador que tomó la empresa en la década de 1880 lo siguieron en lo sucesivo otras muchas, hasta el punto de completar casi las dos terceras partes de maquinaria moderna en la sección de hilados de sus fábricas. Por descontado, el cambio tecnológico no implica necesariamente resultados idénticos, porque el momento en que tiene lugar, la intensidad y las políticas de empleo que lleva consigo -altamente significativas en el caso analizado por apoyarse en mano de obra femenina en la hilatura- no son tampoco idénticos. El éxito de La España Industrial frente al fracaso de Batlló y Batlló, por ejemplo, se debió sin duda a una combinación adecuada de adopción de tecnología madura, que evitó pechar con los elevados costes de innovación que recayeron sobre las pioneras, y una política laboral que simultaneaba el paternalismo con la intransigencia en momentos de conflicto, sin renunciar a drásticos reajustes de empleo. Se trata tan sólo de algunas líneas de respuesta a una pregunta fundamental que espero inviten a nuevas investigaciones.

\section{Fuentes}

Arxiu Nacional de Catalunya (Sant Cugat, Barcelona)

La España Industrial, Libros de Inventario, 1851-1931.

La España Industrial, Libros de Semanales, 1849-1930.

La España Industrial, Estados mensuales, 1854-58 y 1897-1931.

La España Industrial, Comunicados semanales, 1849-50.

La España Industrial, Movimiento Fabril y Mercantil, 1890-1934.

La España Industrial, Memorias de la Dirección, 1888-1930.

La España Industrial, Correspondencia expedida, 1847-1930.

La España Industrial, Correspondencia recibida, 1847-1930.

Muntadas, Matías, Reforma total de la maquinaria en las secciones de preparación de hilados e hilados. Su costo y economía anual, 1887.

Museu d'Estampació (Premià de Mar, Barcelona)

La España Industrial, Datos de la producción, 1889.

Muntadas Hermanos, Copiadores de cartas, 1848-1850.

Archivo de la Cámara de Comercio de Barcelona

La España Industrial, Información a la Cámara Oficial de Industria de Barcelona, 1930, 1, 110-8. 


\section{Bibliografía}

BORDERÍAS, Cristina (en prensa): "Salarios y subsistencia de las trabajadoras y trabajadores de La España Industrial (1849-1868)", Actes del VIII Congrès d'Història de Barcelona.

BOWDEN, Sue, y HIGGINS, David M. (1999): "Productivity on the Cheap. The 'More-Looms' Experiment and the Lancashire Weaving Industry during the Interwars years", Business History, 3 (4), pp. 21-41.

BROADBERRY, Steve N. (1997): The Productivity Race: British Manufacturing in International Perspective 1850-1990, Cambridge, Cambridge University Press.

BROADBERRY, Steve N., y MARRISON, Andrew (2002): “External economies of scale in the Lancashire cotton industry, 1900-1950", Economic History Review, LV, pp. 51-77.

CALVO, Ángel (1986): La transformación de la estructura industrial en Cataluña, 18981920, Barcelona, Universitat de Barcelona (tesis doctoral inédita).

-(1990): "Clientes, amigos y buenos parroquianos", en DELGADO, Josep M. y otros (dirs.), Las relaciones económicas entre Aragón y Cataluña (siglos XVIII-XX), Huesca, Instituto de Estudios Altoaragoneses, pp. 157-175.

-(1999): “La cara conocida. Cambio tecnológico y adaptación al mercado en la industria algodonera catalana (fines del siglo XIX-comienzos del siglo XX)", en GUTIÉRREZ, Miquel (coord.), Doctor Jordi Nadal. La industrialización y el desarrollo económico de España, Barcelona, Universitat de Barcelona, pp. 1.164-1.174.

-(2002): "La indústria cotonera catalana a començaments del segle XX", Recerques, 44, pp. 91-110.

—(2004): "Estrategias de competitividad: la diferenciación del producto en la industria algodonera catalana. Una aproximación desde La España Industrial", en Doctor E. Giralt i Raventós, Estudis d'Història Agrària, 17, pp. 243-264.

CAMPS, Enriqueta (1995): La formación del mercado de trabajo industrial en la Cataluña del siglo XIX, Madrid, Ministerio de Trabajo y Seguridad Social.

CARRERAS, Albert (coord.) (1989): Estadísticas Históricas de España, siglos XIX y XX, Madrid, Fundación Banco Exterior.

CARRERAS, Albert (1990): Industrialización española: estudios de historia cuantitativa, Madrid, Espasa-Calpe.

CARRERAS, Albert, y TAFUNELL, Xavier (coords.) (2005): Estadísticas Históricas de España, siglos XIX y XX, Madrid, Fundación BBVA.

CARRERAS MARÍN, Anna (2001a): "El mercado internacional de tejidos de algodón en 1913 y la industria española", Revista de Historia Económica, XIX, pp. 111-128. -(2001b): "La competitividad de las industria algodonera en el período previo a la I Guerra Mundial: implicaciones de las estrategias de diferenciación de producto 
en los mercados internacionales de tejidos acabados", Actas del VII Congreso de la Asociación Española de Historia Económica, Zaragoza, 19-21 septiembre.

CLARK, Gregory (1987): "Why Isn't the Whole World Developed? Lessons from the Cotton Mills", The Journal of Economic History, XLVII, 1, pp. 141-173.

CLARK, Gregory, y FEENSTRA, Robert (2001): Technology in the Great Divergence, NBER working paper 8.596.

DAVID, Paul A., y WRIGHT, Gavin (1991): "General purpose technologies and surges in productivity", Discussion papers in Economic and Social History, University of Oxford, 31.

DEAN, Edwin R., y SHERWOOD, Mark K. (1994): “Manufacturing costs, productivity, and competitiveness, 1979-1993", Monthly Labor Review, pp. 3-16.

DE GROOT, Gertjan (1995): “Foreign Technology and the Gender Division of Labour in a Dutch Cotton Spinning Mill", en DE GROOT, Gertjan, y SCHROVER, Marlou (eds.), Women Workers and Technological Change in Europe in the Nineteenth and Twentieth Centuries, Londres, Taylor \& Francis, pp. 54-66.

ENRECH, Carles (1996-97): “La reforma de la organización del trabajo en «La España Industrial» a finales de siglo XIX", Sociología del Trabajo, 29, pp. 135-155.

-(1998): "El Llano contra La Montaña. La descualificación del trabajo en la hilatura algodonera catalana a finales del siglo XIX", en CASTILLO, Santiago, y ORTIZ, José María (coords.), Estado, protesta y movimientos sociales, Zarautz, Universidad del País Vasco, pp. 581-595.

-(2003a): El Pla contra La Muntanya. La crisi de la indústria tèxtil del Pla i la colonizació fabril de La Muntanya (1874-1904), Lleida, Universitat de Lleida-Patronat Josep Lladonosa.

-(2003b): "Jerarquía fabril y cualificación en la industria textil durante el último tercio de siglo XIX", Historia Social, 45, pp. 1.001-1.017.

FERRER VIDAL, Josep (1875): Conferencias sobre el arte de hilar y tejer, Barcelona, J. Jesús.

FREIFELD, Mary (1986): "Technological Change and the self-acting mule: a study of skill and the sexual division of labour", Social History, 11, 3, pp. 319-343.

GARCÍA BALAÑ̀̀, Albert (2004): La fabricació de la fabrica. Treball i politica a la Catalunya cotonera (1784-1874), Barcelona, Publicacions de l'Abadia de Montserrat.

GUTIÉRREZ, María Ll. (1997): La España Industrial, 1847-1853. Un model d'innovació tecnològica, Barcelona, Enginyers Industrials de Catalunya, Associació-Col.legi, pp. 193-194.

HALL, H. (1924): “The Driving of Textile Mills", The Electrician, 29.

HUBERMAN, Michael (2001): "When Labour Hires Capital: Evidence from Lancashire, 1870-1914", Economic History Association Annual Meeting. 
Información sobre derecho diferencial de bandera (1867), Madrid, Imprenta Nacional.

INSTITUTO DE REFORMAS SOCIALES (1914): La jornada de trabajo en la industria textil, Madrid, Sucesores de Minuesa de los Ríos.

JABLONSKY, Mary (1995): "Multifactor productivity: cotton and synthetic broadwoven fabrics", Monthly Labor Review, pp. 29-38.

JEREMY, David (2004): "International Changes in Cotton Manufacturing Productivity, 1830s-1950s", en FARNIE, Douglas, y JEREMY, David (eds.), The Fibre that Changed the World. The Cotton Industry in international Perspective, 1600-1990s, Oxford, Oxford University Press, pp. 153-190.

JONES, George T. (1933): Increasing return, Cambridge, Cambridge University Press. LAZONICK, William H. (1981): "Production Relations, Labour Productivity, and Choice of Technique: British and U. S. Cotton Spinning", The Journal of Economic History, XLI, 3, pp. 491-516.

LEUNIG, Timothy (2001a): “New answers to old questions: explaining the slow adoption of ring spinning in Lancashire, 1880-1913", The Journal of Economic History, 61, 2, pp. 439-465.

-(2001b): Britannia ruled the Waves, Working Papers in Economic History, 66/01, London School of Economics.

-(2003): Piece rates and learning: understanding work and production in the New England textile industry a century ago, Working Papers in Economic History, 72, London School of Economics.

LINDNER, Stephan (2002): “Technology and textiles globalization", History and Technology, 18, pp. 1-22.

LLONCH, Montserrat (2004): “Jornada, salarios y costes laborales en el sector textil catalán (1891-1936)", Revista de Historia Industrial, 26, pp. 101-147.

MALUQUER DE MOTES, Jordi (1976): “La estructura del sector algodonero en Cataluña durante la primera etapa de la industrialización (1832-1861)", Hacienda Pública Española, 38, p. 133-148.

—(1985): “La revolución industrial en Cataluña”, en SÁNCHEZ ALBORNOZ, Nicolás, La modernización económica de España, Madrid, Alianza, pp. 199-225.

-(1994): "El índice de la producción industrial en Cataluña. Una nueva estimación (1817-1935)", Revista de Historia Industrial, 5, pp. 45-71.

NADAL, Jordi (1975): El fracaso de la Revolución Industrial en España, 1814-1913, Barcelona, Ariel.

-(1991): "La indústria cotonera", en Història Econòmica de la Catalunya Contemporània. Indústria, transports i finances, Barcelona, Enciclopèdia Catalana, pp. 13-85.

NADAL, Jordi, y SUDRIÀ, Carles (1993): "La controversia en torno al atraso económico español en la segunda mitad del siglo XIX (1860-1913)", Revista de Historia Industrial, 3, pp. 208-209. 
O'BRIEN, Patrick K. (1995): "Is the productivity of labour before 1914 measurable?", Rivista di Storia Economica, XII, 3, p. 439-465.

PRADOS, Leandro (1988): De imperio a nación, Madrid, Alianza.

PRAT, Marc, y SOLER, Raimon (2002): “Weaving the Network? The international marketing's failure of Catalan cotton textiles (1850-1930)", en BONIN, Hubert y otros (eds.), Transnational Companies (19 ${ }^{\text {th }}-20^{\text {th }}$ Centuries), París, P.L.A.G., pp. 219-237.

RIBAS, Enric (1999): “La España Industrial (1851-1936). Análisis económico-financiero de la Compañía", en GUTIÉRREZ, Miquel (coord.), Doctor Jordi Nadal. La industrialización y el desarrollo económico de España, Barcelona, Universitat de Barcelona, pp. 1.125-1.163.

Revista Industrial, marzo 1858.

ROSE, Mary (2000): Firms, Networks, and Business Values: the British and American Cotton Industries since 1750, Cambridge, Cambridge University Press.

ROSÉS, Joan R. (2001): "La competitividad internacional de la industria algodonera española (1830-1860)", Revista de Historia Económica, XIX, pp. 85-110.

-(2004): "La industrialización catalana y el crecimiento de la economía española", (1830-1861)", Revista de Historia Industrial, 25, pp. 49-80.

SÁNCHEZ SUÁREZ, Alex (1989): “La era de la manufactura algodonera en Barcelona, 1736-1839", Estudios de Historia Social, 48-49, pp. 65-114.

-(2000): “Crisis económica y respuesta empresarial. Los inicios del sistema fabril en la industria algodonera catalana, 1797-1839", Revista de Historia Económica, 18, 3, pp. 485-523.

SAXONHOUSE, Gary, y WRIGHT, Gavin (eds.) (2004): “Technological Evolution in Cotton Spinning, 1878-1933", en FARNIE, Douglas, y JEREMY, David (eds.), The Fibre that Changed the World. The Cotton Industry in international Perspective, 16001990s, Oxford, Oxford University Press, pp. 129-152.

SMITH, Angel (1991): "Social conflict and trade-union organisation in the Catalan cotton textile industry, 1890-1914", International Review of Social History, 36, pp. 331-376.

SOLER, Raimon (1999): “"Dios quiera que salgamos de una vez de tan desgraciado negocio». L'adquisició de maquinària de la fàbrica de La Rambla: un episodi de difusió de tecnologia tèxtil (1833-1840)", en GUTIÉRREZ, Miquel (coord.), Doctor Jordi Nadal. La industrialización y el desarrollo económico de España, Barcelona, Universitat de Barcelona, pp. 1.101-1.124.

SUDRIÀ, Carles (1983): “La exportación en el desarrollo de la industria algodonera española, 1875-1920", Revista de Historia Económica, 1, 2, pp. 369-383.

-(1999): "La empresa española y los problemas de competitividad internacional. Una visión desde la industria algodonera", ponencia presentada en la Real Academia de Ciencias Morales y Políticas. 
TAFUNELL, Xavier, y CASTAÑEDA, Lluis (1999): “El mercado mayorista del algodón en Barcelona en el siglo XIX", en GUTIÉRREZ, Miquel (coord.), Doctor Jordi Nadal. La industrialización y el desarrollo económico de España, Barcelona, Universitat de Barcelona, pp. 990-1.005.

VALDALISO, Jesús M. (2004): “La competitividad internacional de las empresas españolas y sus factores condicionantes. Algunas reflexiones desde la historia empresarial", Revista de Historia Industrial, 26, pp. 13-54.

VAN ARK, Bart, y KUIPERS, Simon K. (eds.) (2000): Productivity, Technology and Economic Growth, Boston, Kluwer Academic Publishers.

VON TUNZELMAN, G. Nicholas (1995): “Time-Saving Technical Change: The Cotton Industry in the English Industrial Revolution", Explorations in Economic History, 32 (1), pp. 1-26. 